\title{
Evaluation on China's Anti-drug Efforts and Recommendations
}

\author{
Hongyi LIN \\ Northeastern University, Boston, USA
}

\begin{abstract}
China, the East Asian giant, now faces a growing problem of illicit drug use, which is deeply harmful to its stability. The outcome of intensive enforcements, named "People's anti-drug war", though reaching some accomplishments, is still insufficient to settle this increasingly serious problem. This essay, therefore, highlights the four limits of China's current lawful enforcement through examining the outcome of "anti-drug war" launched in 2015. Furthermore, the essay provides four potential recommendations for the adjustment in China's anti-drug strategy, in terms of its particular political system and geographical environment. With the increasing younger-age trend and geographical expansion of illicit drug problem, the serious situation is calling for a more flexible and artful regulatory framework in China.
\end{abstract}

Keywords: anti-drugs war, drug trafficking, the Gold Triangles, anti-drug strategies

\section{Introduction}

Despite the harsh crackdown from the authorities, use of illegal drugs in China continues unabated. China's drug problems have two particular patterns: (1) The number of addicts that are steadily increasing, (2) the geographical coverage is also increasing extensive. Up to 2016, China has admitted that more than 14 million people or about one percent of the country's massive population have used drugs. It has also disclosed for the first time that drug use has spread to as much as 90 percent of the country's cities, districts, and counties (O'Conner, 2016). It is estimated that China, together with Russian Federation and the United States, accounted for 46 percent of all intravenous drug users in the world (United Nations, 2014).

China's determination on crackdown drug trafficking is strong. China has launched a "People's War on Drugs", appealing to the public for help and offering rewards for catching drug traffickers. In 2014, President XI Jinping and Prime Minister LI Keqiang both "vowed to crack down on drug-related crimes harshly and to contain the spread of drugs" and "called drugs as the enemy of humanity" (XinhuaNet, 2014). The attention of top leadership has translated into increased anti-drug enforcement. The Supreme Court announced in June that drug-related convictions were up 27.8 percent compared to the first five months of 2013 (XinhuaNet, 2014). Furthermore, China's police system is especially keen on catching Chinese celebrities who use drugs, allowing them to send high-profile warnings to the public. However, while some achievements have been made with the intensifying enforcement, the paper demonstrates that China's war on drugs still has some limits which should be of concern. Thus, the paper will point out the limits of current Chinese struggle to combat illicit drugs and seek to propose some potential recommendations on the basis of China's own national condition.

Hongyi LIN, Graduate student, Global Study \& International Relations Program, College of Professional Studies, Northeastern University. 


\section{Literature Review}

On one side, state control is the conventional strategy for the authorities to suppress the rampant phenomenon of illicit drug trafficking. The supporters of state control strategy believe that strong penalties against use, including criminal punishment, are necessary to deter drug use, to facilitate treatment of drug users. In state control area, the sanctions against illegal drug trafficking are legalized and the illicit drugs are forbidden by criminal statutes which created offense related to both use and distribution; no level of use is acceptable and there is no legal source of supply (Erickson, 1993, p. 1155). The theoretical foundation of state control strategy is the classical deterrence theory assuming that crime is motivated by the potential for gain but can be deterred by the prospect of severe punishment (MacCoun, 1993, p. 498). Thus, the states' decriminalization policy can not only achieve general deterrence, but also discourage other potential offenders from involving in criminal acts.

On the other side, some scientists took their emphasis on the social construction of drug addiction, seeking to alleviate rampant illicit drug addiction from social interventions. The scholars in the National Institute on Drug Abuse developed the "research-based prevention principles" based on their research findings on effective drug abuse prevention. They identified several risk factors of transforming an innocent person into a drug abuser and then argued that the prevention program should be tailored to address risks specific to population or audience characteristics, such as age, gender, and ethnicity, to improve program effectiveness (National Institute on Drug Abuse, 2014, p. 24; Spoth, Trudeau, Shin, \& Redmond, 2008, p. 14). Therefore, the preventive approach has been largely cognitive-behavioral approach, with a great attempt to reducing individual risk factors posed on social members.

Two approaches with different emphasis points both have merits but need continued development. Sanctions and heavy punishments against drug use are traditionally a preeminent feature of policy on illegal drugs, yet very little known about the actual preventive effects on these sanctions. Some theorists argued that state controls have failed to demonstrate preventive effects beyond that achieved by underlying illegality of the drug and strong social disapproval (National Research Council, 2001, p. 187). Besides, the preventive approach addressing the risk factors has also been less successful, as many of the most powerful actors are social and impact broad arenas of health, for example, childhood adverse experiences, or delinquency and school failure during adolescence (Gorman \& Conde, 2008, p. 34). Furthermore, prevention efforts to target specific risk factors have not well been implemented, as either these same individuals face a suite of social problems or the type of effort gets wrapped up by a more diffuse health problems.

\section{Methodology}

This paper investigates the outcomes and limits of China's anti-drug campaign in recent years to examine China's strategy against increasing rampant illicit drug problem domestically. The paper argues that China's current anti-drug prohibitionist strategy supported by a solid determination of high-level leaders and its predominant state enforcement ability has become effective in eliminating the illicit drug networks domestically. However, the intense law enforcement also has limitations skillfully and tactfully that need further development. To illustrate the argument more clearly, the data in this paper are coming from various sources, including newspaper articles, online databases, and government reports. 


\section{China's Anti-drug Strategies in 2015 Anti-drug Campaign}

Gilman, Goldhammer, and Weber (2013) termed the approach involving labeling deviant entrepreneurs, their employees, and associates, as well as their customers, as "bad actors" or simply as "criminals" as "moralizing criminological approach", which means the policy choices are out of the intense moral pressure from the public (p. 11). Similar with the enforcement of the U.S government in American's "war on drugs", China's decision-makers also took an aggressive prohibitionist approach to combat drug trafficking. Severe punishment as deterrence, arresting drug-related criminals, and officially called "three circles of barriers" are the three pillars of China's anti-drug enforcement. Drug trafficking is among the few criminal offenses that qualify for the death penalty in China. According to Chinese criminal law, people who smuggle, sell, transport, or manufacture heroin or methamphetamine in an amount greater than 50 grams can be sentenced to 15 years in prison, life imprisonment, and death (National Narcotics Control Commission, 2000). According to a report in 2006, "China executes over four times as many drug-related prisoners as the rest of world" (Macleod, 2006). In terms of the law enforcement, the number of drug cases handled by police of Yunnan in the initial year of "People's war on drugs" 2015, was 98,000, an increase of 4.4 percent from 2004, and in the same period the number of drug suspects that were arrested increased 5.1 percent to 67,000 (Hays, 2015). The "three circles of barriers", which means China's anti-drug trafficking strategies at the tactic level rely on three major lines of defense, including the frontline along the borders, the second line along the highways connecting different providences, and final line establishing inspections at major ports of exits to other providences and countries (ZHANG \& Chin, 2016, p.10).

China's 2015 anti-drug campaign has made significant achievements in weeding out the criminal hubs of illicit drug networks. For instance, in January 2014, Chinese authorities deployed helicopters, speedboats and paramilitary police, seized three tons of methamphetamine in a massive raid on a single southern village called the Boshe notorious for illegal drugs production, and arrested 182 suspects who worked for drug rings (Hays, 2015). Beyond this, China's police enforcements also eradicated many criminal hubs in Yunnan, Guangdong, and Inner Mongolia, where the illicit drugs traffickers are concentrated. Thus, it is easy to conclude that Chinese anti-drug enforcement has strong force and determination on combating the illicit networks.

However, the old pattern of aggressive arrest and punishment of drug-related crimes and widespread political propagandas, without the flexibility and comprehensiveness of tools and methods, seem insufficient to cope with the growing drug problems.

\section{The Limitations of China's Anti-drug Strategies}

\section{The Limits of the Moralizing Approach}

With many achievements notwithstanding, there is no doubt that the moralizing approach has its deficiencies. This moralizing, criminological approach ignores the system dynamic, creates a policy situation that at best devolves into the legal equivalent of whack-a-mole, or pushes the problem over the horizon to some other neighboring jurisdiction (Gilman, Goldhammer, \& Weber, 2013, p. 11). As market-driven enterprises, if the government law enforcement efforts begin to threaten their profits, illicit networks will often take steps to better protect their activities including moving their operations to other states and regions (Deville, 2013, p. 64). 
As what previously mentioned, Chinese police force cracked down the illicit drug businesses in Yunan province and arrested a great number of traffickers, however, simultaneously pushed the much clever and ruthless narcotics supply chain entrepreneurs to the neighboring Golden Triangles, where the Chinese police force is harder to reach. Also, it is impossible for governments to weed out all players in illegal drug supplier chains in their campaign. Thus, the aggressively prohibitionist approach has an inherent problem which is hard to be resolved that "if governments are powerful enough to take down some of the strongest deviant entrepreneurs, then they leave the second-tier players highly incentivized to evolve and innovate so as to avoid the mistakes of their processors" (Gilman et al., 2013, p. 11).

\section{Losing Sight of a Big Picture}

The social and business network in the Chinese illicit drug businesses is essentially an enterprise model, which is heterogeneous and flexible, and formed by relations between criminals and legal actors, settings, and activities (ZHANG \& Chin, 2007, p. 86). The illicit supply chains characterized by the enterprise model tend to be secure, redundant, and resilient to disruption. As Deville (2013) mentions, "the end-to-end supply chain is designed with redundant nodes and simplified roles to limit the potential negative impact that any one individual or group of individuals can have on the success of the overall operation" (p. 65). China's anti-drug police enforcement of crushing local crime organizations is effectively curbing the activities of local fixers by weeding out their "umbrellas" on the Chinese Communist Party (CCP) officials and then disrupting their social network and setting defensive mechanisms in traditional transportation routes rather than cut off their commodity supplies. However, it cannot find a good solution to deal with the complex international supply chain with strong adaptability and secrecy, whose primary target is China.

The drug trafficking chain in China is no longer the group of loosely affiliated individuals in the initial of the 1980s, but a highly sophisticated and well-organized transnational network. For instance, Hong Kong Triads, the biggest narcotic gangs founded in Hong Kong, have extended their operations in southeastern China, while non-mainland Triads gangs are also involved in the trade, operating independently or in conjunction with overseas criminal organizations and contributing to the regionalization of the drug problem (Dupont, 1999, $\mathrm{p}$. 445). In April 2015, China's officials announced the arrest of more than 133,000 people and seizure of 43 tons of illegal narcotics during the five-month antidrug sweep ended in March 2015 (The Global Times, 2015). But according to the report of The New York Times (2015), "Experts say these actions have failed to significantly impede traffickers, 'China likes everyone to think they are in control of everything', said by an anonymous UN official, 'But at the end of the day they have an enormous chemical industry and the state does not have the capability to monitor and control it"'.

\section{Failure on the Regulation of Drug Addicts}

The growing drug trafficking is a market-driven economy. As Deville (2013) mentions, "Illicit networks have no allegiance to any one government, state, or society at large. Instead, these networks are driven by market forces; their loyalty is reserved only for whatever increases their profits" (p. 63). Thus, the reduction of domestic demand is the most effective way in response to the growing drug problems; however, Chinese government fails on the effective management of domestic drug consumption markets. Much in line with the political tradition of the communist party, propaganda campaigns work as main venue to indoctrinate and mobilize the civilians to combat illicit drugs. 
The government has annually portrayed its fight against illicit drugs as a people's war, stirring up public sentiments and enlisting participation from the public (ZHANG \& Chin, 2016, p. 9). It was estimated that in 2011, these mass-based outreach activities distributed more than 30 million copies of campaign materials such as pamphlets and covered more than 110 million people (National Narcotics Control Commission, 2011). Most of the anti-narcotic slogans remain the same from year to year, casting the government in a paternalistic position that asks society in general to save the drug addicts and then urges the drug abusers to treasure their lives and strive to become productive citizens (ZHANG \& Chin, 2016, p. 9). However, a set of data indicates that this propaganda campaign is overall a tragic failure. Between 1991 and 2005 the number of illegal drug users in China increased from 148,000 to 1.05 million (Amnesty International, 2007). Police data from 2006 showed that the number of Chinese taking drugs increased 35\% from 2000 to 2005 alone (Malinowska \& Bartlett, 2006). It is generally accepted that official estimates of drug users vastly under represent the number of users - with some claiming the actual number to exceed reports by 11 to 12 times (Swanström, 2006, p. 115). Therefore, there is no doubt that the increasingly overwhelming number of demanders is the most important driver appealing the drug traffickers, unfortunately, Chinese government seems incapability to have much better solutions except the political campaigns with big fanfare.

\section{Limited Regulation in the Megacities}

China now is experiencing an unprecedented urbanization, millions of Chinese rural populations expanding into the major cities to find new opportunities every day. The most important facet of the link between urbanization and security is probably the growth of slums (Williams, 2013, p. 23), which are called "village-in-city" in China. Another critical dimension is the enormous potential for pernicious interactions between urban growth on the one side and economic crises, high levels of unemployment, and weak and inadequate governance on the other side (Williams, 2013, p. 23). These problems reflect clearly in the geographical characteristics of China's illicit drug problem.

In 2011, over 45 percent of drug crimes in China took place in Guangdong, Chongqing, Zhejiang, Yunnan, and Jiangsu (Tiezzi, 2015). With the exception of Yunnan, the frontier province nearby the Golden Triangles, the other four regions are the most developed areas in China with a significant number of floating populations and inhabitants, far exceeding the number of average megacities. Also, according to an authentic rank in Chinese website, Beijing and Shanghai are the seventh and eighth "drug cities" in 2016, just queuing behind those notorious criminal hubs in China (PaiHangBang, 2017). A report in New York Times (2015) documents that, "A study of sewage in four megacities, published last year in the international journal Science of the Total Environment, reported that meth was omnipresent in Beijing, Shanghai, Guangzhou, and Shenzhen". It is the expanding urbanization, an overwhelming intensity of people especially the significant number of floating populations, and highly international marketing that collaboratively creates a massive pressure on China's anti-drug enforcements in these areas. And it is unlikely that the law enforcement could follow the step of continuing exponential growth of urbanization in China in the future.

\section{Recommendations}

The first recommendation is regulatory harmonization, not eradication. What is certain is that unilateral approaches are almost certainly doomed to failure because that is the source of the arbitrage opportunities that incent deviant entrepreneurs (Gilman et al., 2013, p. 11). Instead of it, the Chinese government can find some 
policy opportunities to change some of the illicit drug producers and traffickers into less harmful channels and even what benefit a broader swathe of humanity, just as what Chinese government has done in dealing with its counterfeiting problem. The more artful enforcement in the local scope requires Chinese government to reduce the unilateral enforcement out of moral outrages but create smart policy levers for changing the local conditions, which provide opportunity for drug traffickers to exploit, such as strategic investment in improving local law enforcement, professionalized scrutiny of the supply chain, and enhancement of legitimate local economic opportunities. In the regional and international scope, the Chinese government should further strengthen law enforcement cooperation with other countries in the field of drug control. Creating a regionally uniform regulatory framework in the Golden Triangles is the right track for China and other states in this region, which face enormous pressures from illicit drug trafficking. Similarly, in combating "threat finance" and associated networks, Lindbolm and Realuyo (2013) explain in their essay, "The international community must collaborate and employ any instruments of national power to dismantle, degrade, disrupt, and deter illicit networks" (p. 113). This idea also is applied to the law enforcement of China's government.

The second recommendation is strengthening the regulatory on the Internet. As Keefe (2013) maintains, "Dispersed organizations, small groups, and individuals communicate, coordinate, and conduct their campaigns in an internetted manner, often without a precise central command" (p. 102). The drug traffickers in China have found the internet as the alternative to trade their commodities, with the networks on ground disrupted by governmental law enforcement. "The Internet has become an increasingly active platform for the organization and operation of drug abuse and trafficking and the criminals also use the Internet to learn how to source material and make drugs illegally" said by LIU Yuejin, director of the ministry's narcotic control bureau, in an interview with a Chinese media (Y-J. LIU, \& M. LI, personal communication, September 25, 2016). Chinese government has noticed it, however, without an effective regulation until now. More than 150 Chinese companies sell $\alpha$-Pyrrolidinopentiophenone ( $\alpha$-PVP), also known as flakka, a dangerous stimulant, this is illegal in the U.S but not in China, and was blamed for 18 deaths in one Florida County. The internet, therefore, has become the new frontier for China's law enforcement to combat the illicit drug trafficking.

The third recommendation is to utilize development assistance programs to support social and economic development in the Golden Triangle countries. The reason behind this recommendation is twofold. Firstly, in many cases, states that host deviant industries recognize and embrace their developmental benefit, for instance, the importance of sex tourism to the economy of Thailand. Just as many countries are willing to tolerate physical pollution as a way to attract investment and jumpstart growth, so other countries are willing to tolerate what we might call social or moral pollution in order to achieve the same ends (Gilman et al., 2013, pp. 5-6). The same situation happens in the Golden Triangle countries, such as Myanmar, Vietnam, and Cambodia, where the illicit drug trafficking is the major source of hard currency. Furthermore, poverty is often a feature of the areas that become criminal hubs. Secondly, because international commerce is such an important element of transnational organized crimes, a failure or a refusal by the relevant authorities to police their own borders creates a decisive strategic advantage for smugglers (Keefe, 2013, p. 102). Likewise, a diminished willingness or capability on the part of law enforcement to crack down on criminality can be major enticement for transnational criminal actors (Keefe, 2013, p. 102). The breakdown of the rule of law makes the civil society within these countries makes the Golden Triangles become an ideal hub of transnational illicit drug traffickers. China, as the leading power of Asia and the biggest victimized state of drug trafficking, can use its economic force to transform the economic structure of neighboring countries into a healthy one. One effective strategy is 
to provide subsidies and tax waivers for Chinese agricultural enterprises to develop economically viable alternatives to opium plantations in the Golden Triangle area. The excellent example is that Yunnan provincial government works with state-owned and private enterprises to train farmers to plant rice, sugarcane, rubber and other crops instead of opium poppy in northern Laos and northern Myanmar in one initiative of opium substitution (SU, 2013, p. 2). It is impossible for the Chinese government to send its troops to other countries directly, but China can support a regionally uniform regulatory framework in the Golden Triangles to officially deploy China's patrol force along the Mekong River to combat drug traffickers alongside the transnational water, just as The Art of War demonstrates, "resisting the enemies outside the national gates". Also, the technological support in law enforcement is also what Chinese government can do to improve the security and stability of this region. It is urgent for China to strengthen the enforcement of such strategies, in terms of the increasing drug threat from the Golden Triangles. For instance, Myanmar is believed to be the single largest supplier of China's drug market. In 2013, 92.2 percent of the heroin and 95.2 percent of methamphetamine seized in China were traced to Myanmar (ZHANG \& Chin, 2016, p. 1).

The last recommendation is to perfect the detoxification system. China's anti-drug war enforcement now is focusing on a criminological approach, weeding out all drug-related criminals but neglects to reduce potential markets of illegal drugs. Lack of standardized management and professional treatment is the major problem in China's detoxification system. According to the investigation of Malinowska-Sempruch (2006), "Those leaving government force-labor and rehabilitation camps have officially reported relapse rates of between 90-95\%; NGO's report the rate to be closer to 99\%" (p. 27). Those interned in China's detoxification center are often offered little treatment other than mandated chants such as "drugs are bad, I am bad", long hours forced labor, and military-style drills. Therefore, China needs to improve its unconditioned detoxification system. The ingrained obstacle for improving detoxification system in China is to change the perceptions of the public and professionals towards drug abuse and addiction and to reduce the stigma and discrimination against drug-dependent individuals, as all the evidence shows that stigma and discrimination are likely to create a vicious cycle of social isolation and marginalization and often lead to failure of treatment (TANG \& HAO, 2007, p. 1061). Besides, establishing a new national intergovernmental office that focuses on issues related to drug addiction treatment is also necessary to accomplish an effective management.

\section{Conclusion}

The purpose of this paper is not to deny the achievements of China's anti-drug war, but to point out the problems which still exist and search for the solutions to deal with it. China, the country experiencing an exponential growth demographically and economically in recent years, faces a bigger pressure from the drug trafficking and other deviant industries compared to most of countries in the world. The drug problem in China is still not optimistic. With $70 \%$ of registered narcotic users under age 35, predictions indicate that drug use is not only growing but also continues to grow at rapid rates regardless of exorbitant punishments (Swanström, 2006, p. 115). Therefore, the serious situation is calling for a more artful and flexible approach and a comprehensive regulatory framework.

\section{Reference}

Amnesty International. (2007, June 28). UN anti-drugs day: Death sentences for drug-crimes rise in the Asia-Pacific Action. Amnesty International. Retrieved from http://asiapacific.amnesty.org/apro/aproweb.nsf/pages/adpan 
Deville, D. (2013). The illicit supply chain. In M. Miklaucic, \& J. Brewer (Eds.), Convergence: Illicit networks and national security in the age of globalization (pp. 63-75). Government Printing Office Press.

Dupont, A. (1999). Transnational crime, drugs, and security in East Asia. Asian Survey, 39(3), 433-455.

Erickson, P. G. (1993). The law, social control, and drug policy: models, factors, and processes. International Journal of the Addictions, 28(12), 1155-1176.

Gilman, N., \& Goldhammer, J., \& Weber, S. (2013). Deviant globalization. In M. Miklaucic, \& J. Brewer (Eds.), Convergence: Illicit networks and national security in the age of globalization (pp. 3-15). Government Printing Office Press.

Gorman, D. M., \& Conde, E. (2008). Further comments on the path to drawing reasonable conclusions about prevention. Addiction, 104(1), 152-154.

Hays, J. (2015). Drug trafficking in China. Facts and Details. Retrieved from http://factsanddetails.com/china/cat11/sub74/entry-4481.html

Keefe, P. R. (2013). The geography of badness: Mapping the hubs of illicit global economy. In M. Miklaucic, \& J. Brewer (Eds.), Convergence: Illicit networks and national security in the age of globalization (pp. 97-111). Government Printing Office Press.

Lindholm, D. C., \& Realuyo, C. B. (2013). Threat finance: A critical enabler for illicit networks. In M. Miklaucic, \& J. Brewer (Eds), Convergence: Illicit networks and national security in the age of globalization (pp. 111-130). Government Printing Office.

MacCoun, R. J. (1993). Drugs and the law: A psychological analysis of drug prohibition. Psychological bulletin, 113(3), 497-512. Retrieved from http://psycnet.apa.org/record/1993-31766-001

Macleod, C. (2006, June 15). China makes ultimate punishment mobile. USA Today. Retrieved from http://usatoday30.usatoday.com/news/world/2006-06-14-death-van_x.htm

Malinowska-Sempruch, K., \& Bartlett, N. (2006). Who needs protecting? Rethinking HIV, drugs, and security in the China context. China and Eurasia Forum Quarterly, 4(1), 26.

National Institute on Drug Abuse. (2014). Drugs, brains, and behaviors, the sciences of addiction. NIH.org. Retrieved from https://www.drugabuse.gov/publications/drugs-brains-behavior-science-addiction/preventing-drug-abuse-best-strategy

National Narcotics Control Commission. (2000). Annual report on drug control in China, 2000. Beijing: National Narcotics Control Commission. Retrieved from http://www.mps.gov.cn/n16/n80209/n80481/n804535/804639.html

National Narcotics Control Commission. (2011). Annual report on drug control in China, 2011. Beijing: National Narcotics Control Commission. Retrieved from http://www.bjjdzx.org/157/2011-10-14/45547.htm

National Research Council. (2001). Informing America's policy on illegal drugs: What we don't know keeps hurting us. National Academies Press.

O'Conner, S. (2016, July 18). Meth precursor chemicals from China: Implications for the United States. U.S-China Economic and Security Review Commission. Retrieved from https://www.uscc.gov/sites/default/files/Research/Staff\%20Report_ PrecursorChemicalReport\%20071816_0.pdf

PaiHangBang. (2017, January 13). The rank of drug-city in China. Paihangbang.com. Retrieved from https://www.phb123.com/city/tese/10361.html

Spoth, R., Trudeau, L., Shin, C., \& Redmond, C. (2008). Long-term effects of universal preventive interventions on prescription drug misuse. Addiction, 103(7), 1160-1168.

SU, X. (2013). China's antidrug policies in Southeast Asia's Golden Triangle. Asia Pacific Bulletin. Retrieved from https://scholarspace.manoa.hawaii.edu/handle/10125/30620

Swanström, N. (2006). Narcotics and China: an old security threat from new sources. China and Eurasia Forum Quarterly, 4(1), $113-131$.

TANG, Y. L., \& HAO, W. (2007). Improving drug addiction treatment in China. Addiction, 102(7), 1057-1063. Retrieved from http://onlinelibrary.wiley.com/doi/10.1111/j.1360-0443.2007.01849.x/full

The Global Times. (2015, October 08). Grieving Australian father prompts China to address deadly synthetic drug exports. Global Time.org. Retrieved from http://www.globaltimes.cn/content/946073.shtml

Tiezzi, S. (2015). China's growing drug problem. The Diplomat. Retrieved from https://thediplomat.com/2015/05/chinas-growing-drug-problem/

Williams, P. (2013). Lawlessness and disorder: An emerging paradigm for the 21th century. In M. Miklaucic, \& J. Brewer (Eds.), Convergence: Illicit networks and national security in the age of globalization (pp. 15-37). Government Printing Office Press. 
Xinhuanet. (2014, June 25). Chinese leaders vow to contain drugs. Xinhua.net. Retrieved from http://news.xinhuanet.com/english/china/2014-06/25/c_133437873.htm

ZHANG, S. X., \& Chin, K. L. (2007). The Chinese connection: Cross-border drug trafficking between Myanmar and China. Final Report. National Institution of Justice. Retrieved from http://www.jstor.org/stable/j.ctt15r3z7r 